\title{
Recessive congenital methemoglobinemia in immediate generations
}

\author{
Deniz Aslan¹, Gülsan Türköz-Sucak², Melanie Joan Percy ${ }^{3}$ \\ ${ }^{1}$ Division of Hematology, Department of Pediatrics, Gazi University, Faculty of Medicine, ${ }^{2}$ Division of Hematology, \\ Department of Internal Medicine, Gazi University, Faculty of Medicine, Ankara, Turkey, ${ }^{3}$ Centre for Cancer Research \\ and Cell Biology (CCRCB), Queen's University Belfast, Belfast, United Kingdom. \\ E-mail: daslan@gazi.edu.tr and drdagutf@ttmail.com
}

Received: 16 March 2015, Revised: 24 February 2016, Accepted: 10 March 2016

\begin{abstract}
SUMMARY: Aslan D, Türköz-Sucak G, Percy MJ. Recessive congenital methemoglobinemia in immediate generations. Turk J Pediatr 2016; 58: 113-115.

We report herein on our observation of recessive congenital methemoglobinemia (type I), an autosomal recessive disorder, in immediate generations (in a mother and her daughter). Molecular analysis revealed a mechanism of inheritance not reported previously, despite the high probability of occurrence in autosomal recessive disorders. This report is also the first publication describing an extremely rare mutation (Arg50Gln) causing this disorder in the Turkish population.
\end{abstract}

Key words: recessive congenital methemoglobinemia, immediate generations, Arg50Gln mutation, Turkish patient.

Recessive congenital methemoglobinemia ( $R C M)$ is an autosomal recessive (AR) disorder due to NADH-cytochromeb5 reductase (cytb5r) deficiency ${ }^{1}$. This enzyme exists in both soluble and membrane-bound forms. The soluble erythrocytic isoenzyme is involved in methemoglobin reduction, while the membrane-bound enzyme participates in fatty acid desaturation and drug metabolism. All isoforms of human cytb5r are synthesized by a single gene, $C Y B 5 R 3^{2}$. This disorder occurs as a result of mutations in this gene and has two clinical phenotypes: type I, benign form with mild cyanosis, and type II, severe form with cyanosis and neurological impairment. In type I RCM, cytb5r deficiency is restricted to erythrocytes, while in type II RCM, a profound enzyme deficiency in all tissues is present. To date, 50 different mutations in CYB5R3 leading to RCM have been described ${ }^{3}$. As it is AR in character, the condition is only manifested in individuals having two copies of the mutant allele. A child born to two parents carrying one copy each of the mutant allele becomes symptomatic, with a classical risk of $25 \%$. Accordingly, the RCM patients reported thus far are individuals born to heterozygous and asymptomatic parents. We herein present our observation of an AR disorder uncommonly derived in immediate generations.

\section{Case Report}

The proband is a 51-year-old woman of Turkish origin, who was found incidentally to have an elevated methemoglobin level. Her history revealed perioral cyanosis from childhood. She was investigated for this symptom for the first time one month ago when her daughter was admitted to our hospital for diarrhea. During the assessment of diarrhea, arterial blood gas test was ordered for the daughter and an elevated level of methemoglobin was detected (12.7\%, normal range $0-1.5 \%)$. Subsequent parental study showed that the mother also had a high level of methemoglobin (16.2\%). They were both consulted to Hematology Department.

The parents of the proband were first-degree relatives and she had three healthy siblings. Cyanosis had been considered a sequela of measles in early childhood from which she had recovered. Physical examination revealed cyanosis of perioral skin and oral mucosa. Her husband was 55 years old and healthy without cyanosis. They were not related but were from the same region. The daughter was 17 years 
Table I. Some Clinical and Laboratory Findings of Family V.

\begin{tabular}{lcccccccc}
\hline $\begin{array}{l}\text { Family } \\
\text { member }\end{array}$ & $\begin{array}{c}\text { Age } \\
\text { (years) }\end{array}$ & $\begin{array}{c}\text { Clinical } \\
\text { presentation }\end{array}$ & $\begin{array}{c}\text { MetHb } \\
(\%)\end{array}$ & Mutation & Exon & Change & $\begin{array}{c}\text { Disease } \\
\text { status }\end{array}$ & $\begin{array}{c}\text { Clinical } \\
\text { phenotype }\end{array}$ \\
\hline Mother & 51 & $\begin{array}{c}\text { Mild } \\
\text { cyanosis }\end{array}$ & 16.2 & $\begin{array}{c}\text { CGG to } \\
\text { CAG at } \\
\text { codon 50 }\end{array}$ & 2 & Arg50Gln & Homozygous & Type I \\
Father & 55 & None & 0.5 & $\begin{array}{c}\text { CGG to } \\
\text { CAG at } \\
\text { Codon 50 }\end{array}$ & 2 & Arg50Gln & Heterozygous & - \\
Daughter & 17 & $\begin{array}{c}\text { MGG to } \\
\text { Cyanosis }\end{array}$ & 12.7 & $\begin{array}{c}\text { CAG at } \\
\text { codon 50 }\end{array}$ & 2 & Arg50Gln & Homozygous & Type I \\
\hline
\end{tabular}

CGG: Cytosine-Guanine-Guanine, CAG: Cytosine-Adenine-Guanine, Arg50Gln: Arginine50Glycine

old and healthy except for mild perioral and buccal cyanosis that has been incidentally observed only recently. No cardiac, pulmonary or intestinal disorder was present, and no environmental toxicity was determined.

Based on the clinical and laboratory findings, hereditary methemoglobinemia was considered. Hemoglobin analysis by high performance liquid chromatography (HPLC) showed normal results. DNA was isolated by standard protocols, after obtaining informed consent, and polymerase chain reaction (PCR)-direct sequencing of the CYB5R3 gene was performed as previously described ${ }^{4}$. Molecular analysis showed that the family had the same mutation, as CGG to CAG at codon 50 in exon 2, resulting in Arg50Gln. The father was heterozygous and both mother and daughter were homozygous. Family tree, sequence analysis and clinical laboratory data of the core family are shown in Figures 1A and $\mathrm{B}$, and Table I, respectively. Ascorbic acid was initiated for cosmetic purposes and the mild cyanosis disappeared.

\section{Discussion}

Cyanosis may develop due to reduced oxygen supply to the tissues resulting from the production of non-functional hemoglobin containing oxidized $\mathrm{Fe}^{+3}$, namely methemoglobin. Methemoglobinemia can develop by three distinct mechanisms: genetic mutation resulting in the presence of abnormal hemoglobin, a deficiency of methemoglobin reductase enzyme, and toxin-induced oxidation of hemoglobin 4 .

In the absence of environmental toxins, the presence of cyanosis suggests a hereditary cause. In case of cyanosis present in immediate generations, probable causes are limited to autosomal dominantly inherited disorders, such as "hemoglobin $\mathrm{M}$ disease" ( $\mathrm{HbM}$ disease). Hemoglobin $M$ disease results from amino acid substitutions in the heme binding pocket of globin chains ${ }^{4}$. Such structural alteration can lead to spontaneous oxidation of the $\mathrm{Fe}^{+2}$ ion embedded in heme and cyanosis may develop

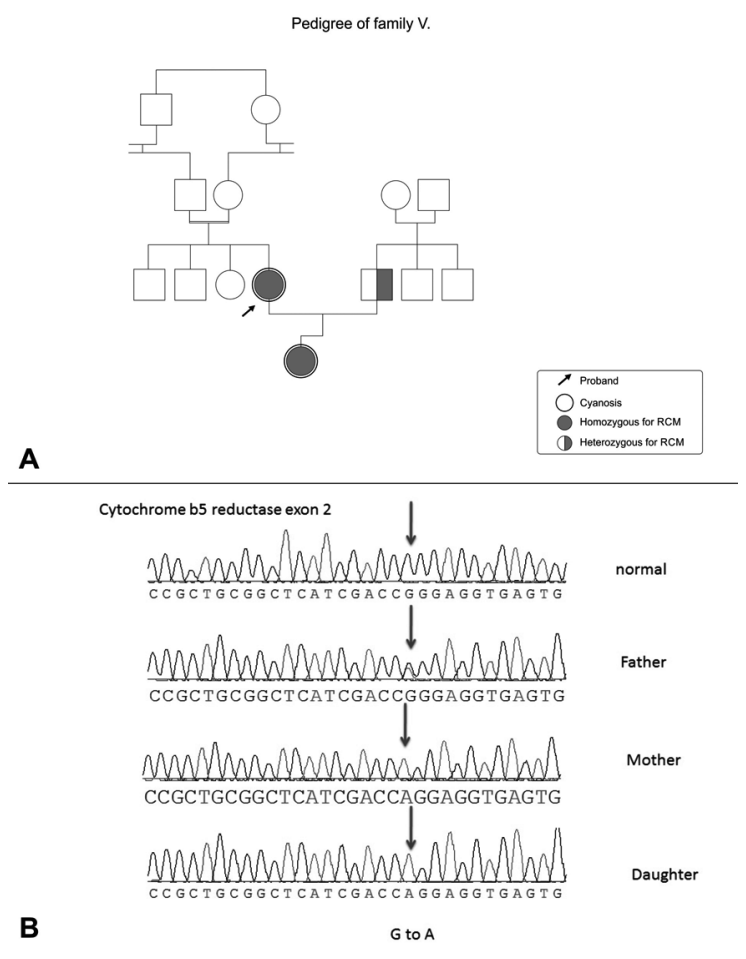

Fig.1. (A) Family tree indicating the position of the mother and daughter with cyanosis due to recessive congenital methemoglobinemia (RCM).

(B) The sequences with the homozygous mutation found in the patient and daugther (as compared to wild type), and heterozygous mutation identified in the husband. 
from birth. The diagnosis depends on the determination of $\mathrm{HbM}$ variants or on molecular analysis. In this family, the lack of abnormal hemoglobins with HPLC excluded HbM disease.

Recessive congenital methemoglobinemia is the most frequent cause of hereditary cyanosis. Only homozygous individuals (more correctly, individuals having two copies of the mutant allele) are cyanotic. How could both a mother and her daughter be homozygous for an AR disorder? The situation might be explained by de novo RCM, as the rarest cause. Similar to the other genetic hemoglobin disorders ${ }^{5}$, RCM might also develop de novo. While the development of a de novo disease in immediate generations is extremely rare, it cannot be excluded. In this family, however, the clinical laboratory features are not suggestive of de novo development of RCM. The other explanation might be uniparental disomia (UPD). This disorder should be suspected in an individual manifesting a recessive disorder, where only one parent is symptomatic. Interestingly, UPD has been described in $\mathrm{RCM}^{6}$, and we have experienced this situation firsthand (Percy MJ, unpublished observation). In this family, both parents had the same mutation as that affecting the child and further evaluation for UPD is unnecessary. The most likely situation is the fact that one parent has homozygous and the other has heterozygous RCM. This is hypothetically possible and widely expected in AR disorders, especially among consanguineous populations; since one parent has two mutant alleles and the other parent has one, the risk of a child born with two mutant alleles is $50 \%$, rather than the usual $25 \%$ in recessive diseases. However, and surprisingly, it has not been reported previously in RCM. This basic pattern of Mendelian inheritance should be borne in mind, especially in populations with a high rate of consanguinity, and for those disorders that are mildly symptomatic even in homozygous state, such as RCM type I. This condition should be ruled out first, before investigating more sophisticated rare conditions.

This mutation was first described in 20017. In that Spanish family, the father was heterozygote for this mutation and the mother was heterozygote for a different mutation. Two of their children were compound heterozygotes. One child had a methemoglobin level of $6 \%$, reduced enzyme activity, and cyanosis. The other was noncyanotic with a methemoglobin level of $2 \%$ and a low enzyme activity. Our patients were in homozygous state, and in this regard, they are the first such cases. Based on the clinical laboratory features of both previous cases and our patients, we can conclude that this mutation may lead to a mild phenotype, which might have contributed to the delayed diagnosis in our family.

Although specific mutations in the CYB5R3 gene may not be exclusive to each type ${ }^{8}$, molecular diagnosis of RCM is important, particularly for type II disease. For genetic counseling, mutational patterns of different populations are required. In this regard, this report also contributes to the current knowledge on the molecular basis of Turkish RCM cases.

\section{REFERENCES}

1. Percy MJ, Lappin TR. Recessive congenital methaemoglobinaemia: cytochrome $\mathrm{b}(5)$ reductase deficiency. Br J Haematol 2008; 141: 298-308.

2. Tomatsu S, Kobayashi Y, Fukumaki Y, Yubisui T, Orii T, Sakaki Y. The organization and the complete nucleotide sequence of the human NADH-cytochrome b5 reductase gene. Gene 1989; 80: 353-361.

3. Ewenczyk C, Leroux A, Roubergue A, et al. Recessive hereditary methaemoglobinaemia, type II: delineation of the clinical spectrum. Brain 2008; 131: 760-761.

4. Percy MJ, McFerran NV, Lappin TR. Disorders of oxidised haemoglobin. Blood Rev 2005; 19: 61-68.

5. Viana MB, Belisário AR. De novo alpha 2 hemoglobin gene (HBA2) mutation in a child with hemoglobin $\mathrm{M}$ Iwate and symptomatic methemoglobinemia since birth. Rev Bras Hematol Hemoter 2014; 36: 230-234.

6. Huang YH, Tai CL, Lu YH, Wu TJ, Chen HD, Niu DM. Recessive congenital methemoglobinemia caused by a rare mechanism: maternal uniparental heterodisomy with segmental isodisomy of a chromosome 22. Blood Cells Mol Dis 2012; 49: 114-117.

7. Dekker J, Eppink MH, van Zwieten R, et al. Seven new mutations in the nicotinamide adenine dinucleotide reduced-cytochrome $\mathrm{b}(5)$ reductase gene leading to methemoglobinemia type I. Blood 2001; 97: 1106-1114.

8. Percy MJ, Barnes C, Crighton G, Leventer RJ, Wynn $\mathrm{R}$, Lappin TR. Methemoglobin reductase deficiency: novel mutation is associated with a disease phenotype of intermediate severity. J Pediatr Hematol Oncol 2012; 34: 457-460. 